\title{
INFLUENCE OF MARINE FUEL PROPERTIES ON IGNITION, INJECTION DELAY AND ENERGY EFFICIENCY
}

\author{
Sergejus LEBEDEVAS ${ }^{1}$, Nadežda LAZAREVA ${ }^{2}$, Paulius RAPALIS ${ }^{3 *}$, \\ Vygintas DAUKŠYS ${ }^{4}$, Tomas ČEPAITIS ${ }^{5}$ \\ 1,2,4,5 Dept of Marine Engineering, Klaipeda University, Lithuania \\ ${ }^{3}$ Waterborne Transport and Air Pollution Laboratory, Marine Research Institute, Klaipeda University, Lithuania
}

Submitted 13 March 2020; resubmitted 14 August 2020, 15 October 2020; accepted 17 April 2021

\begin{abstract}
According to the International Council on Combustion Engines (CIMAC) and International Maritime Organization (IMO) statistics, the rational selection of Marine Bunker Fuel (MBF) properties is an effective way to improve operating conditions and energy efficiency of all types of marine Diesel Engines (DEs). The publication presents the results of studies on the influence of heavy and distillate MBF properties on the characteristics of different DE types: high-speed (Caterpillar 3512B, MTU 8V 396TB), medium-speed (SKL VDS 48/42, ChN 26.5/31) ir low-speed (MAN B\&W 6S60MC). The aim of work is to form a methodological framework for assessing the influence of marine fuel properties on the energy performance of different types of ship power plants. Numerical methods show that in the case of unfavourable selection of the density and viscosity of marine fuels regulated by the standard ISO 8217:2017, the changes in specific fuel consumption $b_{e}$ reach up to $10 \%$ low-speed, $4 \ldots 7 \%$ medium-speed, and $2 \ldots 3 \%$ high-speed DEs. As the density varies from light grades to $1010 \mathrm{~kg} / \mathrm{m}^{3}$, the change in $b_{e}$ is $3 \ldots 4 \%$. At low viscosity, as the density increases to $1030 \mathrm{~kg} / \mathrm{m}^{3}$, the low-speed engine comparative fuel consumption increases by $5 \%$. It is recommended not to use fuel with a density $>1010 \mathrm{~kg} / \mathrm{m}^{3}$ and a viscosity $<300 \ldots 400 \mathrm{~mm}^{2} / \mathrm{s}$. Developed solutions for the rational selection of bunkered marine fuel properties for a specific DE model trough the influence of density and viscosity on fuel injection and combustion characteristics based on multiparametric diagrams of relative fuel consumption change.
\end{abstract}

Keywords: diesel engines, fuel consumption, viscosity, density, activation energy.

\section{Notations}

Abbreviations:

BSFC - brake specific fuel consumption;

CCAI - calculated carbon aromatic index;

CDF - computational fluid dynamics;

CDS - conventional design system;

$\mathrm{CI}$ - cetane index;

CIMAC - International Council on Combustion Engines;

$\mathrm{CN}$ - cetane number;

$\mathrm{CO}$ - carbon monoxide;

$\mathrm{CO}_{2}$ - carbon dioxide;

$\mathrm{CR}$ - common rail;

DMA - MBF markings according to the ISO 8217: 2017 standard;

DMB - MBF markings according to the ISO 8217: 2017 standard;

DE - diesel engine;

EEDI - energy efficiency design index;
HC - hydrocarbon;

HFO - heavy fuel oil;

IMO - International Maritime Organization;

MARPOL - International Convention for the Prevention of Pollution from Ships;

$\mathrm{MBF}$ - marine bunker fuel;

MDO - marine diesel oil;

MM - mathematical model;

NOP - nozzle opening pressure;

RMF - residual marine fuel;

RMG - MBF markings according to the ISO 8217:2017 standard;

RMK - MBF markings according to the ISO 8217:2017 standard;

SPO - sewage sludge pyrolysis oil.

Variables and functions:

$A_{p}$ - area of plunger $\left[\mathrm{mm}^{2}\right]$;

$B$ - fuel bulk modulus [MPa];

$b_{e}-$ specific fuel consumption $[\mathrm{g} / \mathrm{kW} \cdot \mathrm{h}]$;

${ }^{*}$ Corresponding author. E-mail: paulius.rapalis@ku.lt 
$b_{e i}$ - the current $(i=1)$ and predicted $(i=2)$ values of specific fuel consumption $[\mathrm{g} / \mathrm{kW} \cdot \mathrm{h}]$;

$C N_{E_{a} 30}$ - cetane number calculated at $\tau_{i}$, when activation energy is $30 \mathrm{~kJ} / \mathrm{mol}$;

$E_{a}$ - activation energy $[\mathrm{kJ} / \mathrm{mol}]$;

$E_{a C N 45}$ - activation energy, calculated at $\tau_{i}$, when cetane number is $45[\mathrm{~kJ} / \mathrm{mol}]$;

$H_{u}$ - calorific value $[\mathrm{J} / \mathrm{kg}]$

$n$ - engine crankshaft speed $\left[\mathrm{min}^{-1}\right]$;

$N O P$ - nozzle opening pressure [MPa];

$P_{e}$ - engine power $[\mathrm{kW}]$;

$P_{0}$ - residual pressure in system [MPa];

$P_{m e}$ - mean effective pressure [bar];

$P_{f i}$ - pressure in the cylinder at the beginning of the fuel injection [MPa];

$P_{k}$ - compressor pressure [bar];

$P_{\max }-$ maximum cylinder pressure [bar];

$R$ - gas constant $[\mathrm{J} /(\mathrm{kg} \cdot \mathrm{K})]$;

$t$ - the temperature at which the fuel viscosity is determined $\left[{ }^{\circ} \mathrm{C}\right]$;

$T_{f i}$ - temperature in the cylinder at the beginning of the fuel injection $[\mathrm{K}]$;

$T_{g}$ - exhaust gas temperature after turbine $[\mathrm{K}]$;

$T_{t}$ - exhaust gas temperature before turbine $[\mathrm{K}]$;

$V_{f}$ - compression fuel volume $\left[\mathrm{mm}^{3}\right]$;

$v_{\varphi}$ - plunger speed $\left[\mathrm{mm} /{ }^{\circ} \mathrm{c}\right.$.r.a];

$w_{a}$ - mass fraction of ash in fuel [\%];

$w_{s}$ - mass fraction of sulphur in fuel [\%];

$w_{w}$ - mass fraction of water in fuel [\%];

$\alpha$ - excess air ratio $[-]$;

$\beta_{i}$ - conversation factor by density ( $i=1,2$ for first and second fuel);

$\varphi_{i n j}-$ actual fuel injection angle [ ${ }^{\circ}$ c.r.a];

$\Delta \varphi_{i n j}$ - crankshaft angle interval between the fuel supply start by the pump and fuel injection into the engine cylinder [ ${ }^{\circ}$ c.r.a];

$\gamma_{i}$ - conversation factor by viscosity $(i=1,2$ for first and second fuel);

$v$ - kinematic viscosity $\left[\mathrm{mm}^{2} / \mathrm{s}\right]$;

$\rho$ - density $\left[\mathrm{kg} / \mathrm{m}^{3}\right]$;

$\rho_{15}$ - fuel density at $15^{\circ} \mathrm{C}\left[\mathrm{kg} / \mathrm{m}^{3}\right]$;

$\tau_{i}-$ ignition delay period $\left[{ }^{\circ} \mathrm{C} . r . \mathrm{a}\right]$;

$\tau_{i C N}$ - ignition delay period calculated from $\mathrm{CN}$ [ ${ }^{\circ} \mathrm{C}$.r.a];

$\tau_{i E_{a}}$ - ignition delay period calculated from $E_{a}\left[{ }^{\circ}\right.$ c.r.a].

\section{Introduction}

Increasing energy efficiency and reducing environmental pollution have become key components of sustainable transport development (EC 2011). According to Eurostat, the transportation sector accounts for $24 \%$ of total $\mathrm{CO}_{2}$ emissions, of which maritime transport emits $2.6 \%$, amounting to 932 million tons by mass (Olmer et al. 2017; Eurostat 2021). In order to ensure cleaner and greener shipping, in 2011, the IMO extended MARPOL Annex VI and introduced the EEDI for ships (Wilkison 1985; Schobert 2013) between 3000 and $15000 \mathrm{dwt}$. This indicator is intended to encourage ship owners to seek energy efficiency. The strategy foresees a 50\% reduction in $\mathrm{CO}_{2}$ emissions from ships by 2050 compared to 2008 (IMO 2021). Structurally, the EEDI equation is described in terms of the vessel power, specific fuel consumption, carbon content in fuel, deadweight, and speed. Accordingly, $\mathrm{CO}_{2}$ emissions can be reduced by reducing the fuel consumption, using less carbon, or improving the ship design. However, the actual balance of fossil fuel use to alternative energy sources is 97 to 3\% (Li, Loo 2014; García-Olivares et al. 2018). HFO is economically competitive and constitutes the bulk of consumed fuel in maritime transport, with approximately $70 \%$ of the total balance (Olmer et al. 2017; Helgason et al. 2020). A total of 70000 vessels were using HFO in 2019 (Fun-Sang Cepeda et al. 2019). It is therefore necessary to look for other means of improving the energy efficiency of ships, either by optimising speed or by reducing fuel consumption (Xing et al. 2019). At this time most research focused on biofuel - diesel and diesel additives with a goal to reduce harmful pollutant emission and improve efficiency (Labeckas et al. 2006; Fayyazbakhsh, Pirouzfar 2017; Maawa et al. 2020). A study that analysed diesel fuel properties influence on engine performance found that there some correlation between fuel density and $\mathrm{CN}$, aromatic $\mathrm{HC}$ fraction, heat value and in addition, it was found that $\mathrm{CO}$ and $\mathrm{HC}$ emissions increase with the increase of fuel density (Liu et al. 2018). Soto et al. (2018) analysed the activation energy of diesel and biodiesel fuels and found that lower activation energy of biodiesel has positive effects on engine torque, power and thermal efficiency. Studies that analyse MBF, however, are very rare. Research of HFO injection and combustion properties performed by researchers Takasaki et al. (1999) and Wakuri et al. (1990) found that HFO exhibits poor dispersion, longer ignition delay and lower heat release in comparison with MDO. Wakuri et al. (1990) also determined that higher injection pressure, improved air circulation and increased temperature in combustion chamber, in comparison to lighter fuels, is necessary to improve HFO combustion. More recent study targeted the goal of improved HFO combustion by mixing HFO with SPO, mixtures displayed reduced viscosity and improved combustion performance (Kuan et al. 2020). Jang analysed influence of different fuel additives on MBF and found that there was significant influence on ignition delay and combustion duration as well as particulate matter emissions (Jang, Choi 2016). Fostiropoulos et al. (2020) attempted to improve atomization of HFO by making fuel-water emulsions. In this study fuel - water emulsion droplet evaporation was simulated to better understand and improve injection.

Efficient use of MBF is also difficult because of wide range of fuel types, ship fuel standards govern light fraction distillates (4 species) and HFO (11 types) (ISO 8217:2017). Heavy fuel consists of a mixture of heavy oil fractions and distillates of different proportions. This explains the ex- 
tensive selection of heavy fuel types on the market with a viscosity from 10 to $700 \mathrm{~mm}^{2} / \mathrm{s}$. The combination of the nature of heavy fuel and the wide range of fuel brands makes it difficult to unify the quality parameters determining the efficiency of ship propulsion plant operations.

The different types of propulsion plants used in maritime transport (low, medium, and high-speeds) are also important in this context, with peculiarities of work process performance as well as "sensitivity" to fuel quality (Voznickij, Punda 2010). One key factor in this chain is the deviation of the flammability properties, calorific value, and actual injection phase due to changes in the physical-chemical properties of the fuel from the reference values suggested by DE manufacturers (Wright 2017).

MBF standards do not regulate the number of parameters determining the energy efficiency of the DEs. MBF is essentially described by 2 properties related to combustion characteristics: (1) density and (2) viscosity. All other properties describe fuel purity. Light MBF ignition parameters are defined by the CI, and heavy MBF by the CCAI.

Since the 1980s, MBF ignition and combustion properties have been indirectly regulated by standards. The Shell Corporation suggested that the MBF's ignition rating can be evaluated analytically by the CCAI, which is dependent on the paraffinic and aromatic HC balance in marine fuels (Wilkison 1985; Schobert 2013). The CCAI is based on the relationship between the density and viscosity of HC groups (paraffinic, aromatic):

"» the paraffinic HCs group exhibit strong self-ignition characteristics, which provide a relatively short ignition delay period $\tau_{i}$ and controlled diffusion phase combustion, high energy efficiency parameters, and limited mechanical and thermal loads on parts (Cataluña, Da Silva 2012; MFAME 2015; Wright 2017);

"» the aromatic group HCs are characterised by poor flammability characteristics and, in contrast to paraffinic HCs, exhibit a counterproductive effect on DE work processes. However, paraffinic HCs have lower density and viscosity compared to aromatic HCs (Schobert 2013; Totten et al. 2019).

Mathematically, these dependencies are described by the following CCAI equation:

$$
\begin{aligned}
& C C A I=\rho_{15}-81-141 \cdot \lg (\lg (v+0.85))- \\
& 483 \cdot \lg \left(\frac{t+273}{273}\right) .
\end{aligned}
$$

A higher CCAI index indicates a lower fuel flammability. Therefore, in order to select MBF with superior flammability characteristics, it is appropriate to opt for combinations with the highest viscosity and a lower density from the available ranges of $\rho$ and $v$. As observed by the relatively free selection of MBF $\rho$ and $\nu$ values, based on statistical data (certificates from the Saybolt laboratory http://www.saybolt.com), the $\rho$ and $v$ ranges exhibit no obvious interdependencies.

As the fuel species used in the propulsion plant have expanded, compared to the fuels in the proposed CCAI formula, problems have arisen with poor MBF autoignition and combustion characteristics. Therefore, the CIMAC statistics indicate that numerous significant problems exist in the operation of diesel power plants for all vessel types (CIMAC 2011; MFAME 2015). Excessive fuel operating costs, often caused by poor MBF ignition characteristics and the deterioration of energy efficiency, difficult DE start-up, especially from the "cold" state, unstable DE functioning in low-speed operation modes, and increased wear of cylinder-piston parts owing to the increased temperature of the combustion products have been observed (Mollenhauer, Tschöke 2010; Reif 2014).

On this basis, in order to contribute to the improvement in the energy efficiency of MBF consumption, the rational selection of MBF properties is important. The publication presents the results of research which aim is to study the influence of the properties of a wide range of marine fuels on the operational energy characteristics of different types of ship power plants and to develop methodological solutions for the selection of rational combinations of properties:

"» analytical relationships between marine fuel density and viscosity parameters and activation energy as well as between marine fuel density and fuel injection phase were established, which are necessary for adequate mathematical modelling of the DE indicated process;

"I» new data, detecting the effect of the interaction of the regulated properties of the fuel (density and viscosity) on the parameters of energy efficiency and reliability of various types of DEs (low, medium and high-speed) were obtained.

\section{Materials and methods}

Based on the physical characteristics of the fuel properties recommended by manufacturers in the technical documentation, density and viscosity combinations were selected for each DE type from the $\rho-v$ field. In Figure 1, the points in the $\rho-v$ field describe the combinations of MBF properties for the respective engines.

The main types of marine DEs selected for research were low, medium and high-speed CDS and CR systems. Specifications of the DE technical parameters presented in the Table 1.

According to many experimental and numerical studies, MBF density and viscosity affect the energy efficiency parameters of $\mathrm{DE}$ through the influence of fuel spray quality factor (uniformity, fineness), the work of the initial phase of the mixture, the self-ignition of the fuel properties, as well as the fuel energy content. In a single-zone $\mathrm{MM}$, these factors, in turn, manifest themselves through the influence of changes in the actual fuel injection angle / phase, induction period, fuel cyclic portion due to $H_{u}$.

During this research stage multi-dimensional (DieselRK software - https://diesel-rk.bmstu.ru) and single-zone (IMPULS software - Voznickij, Punda (2010)) models were used. 


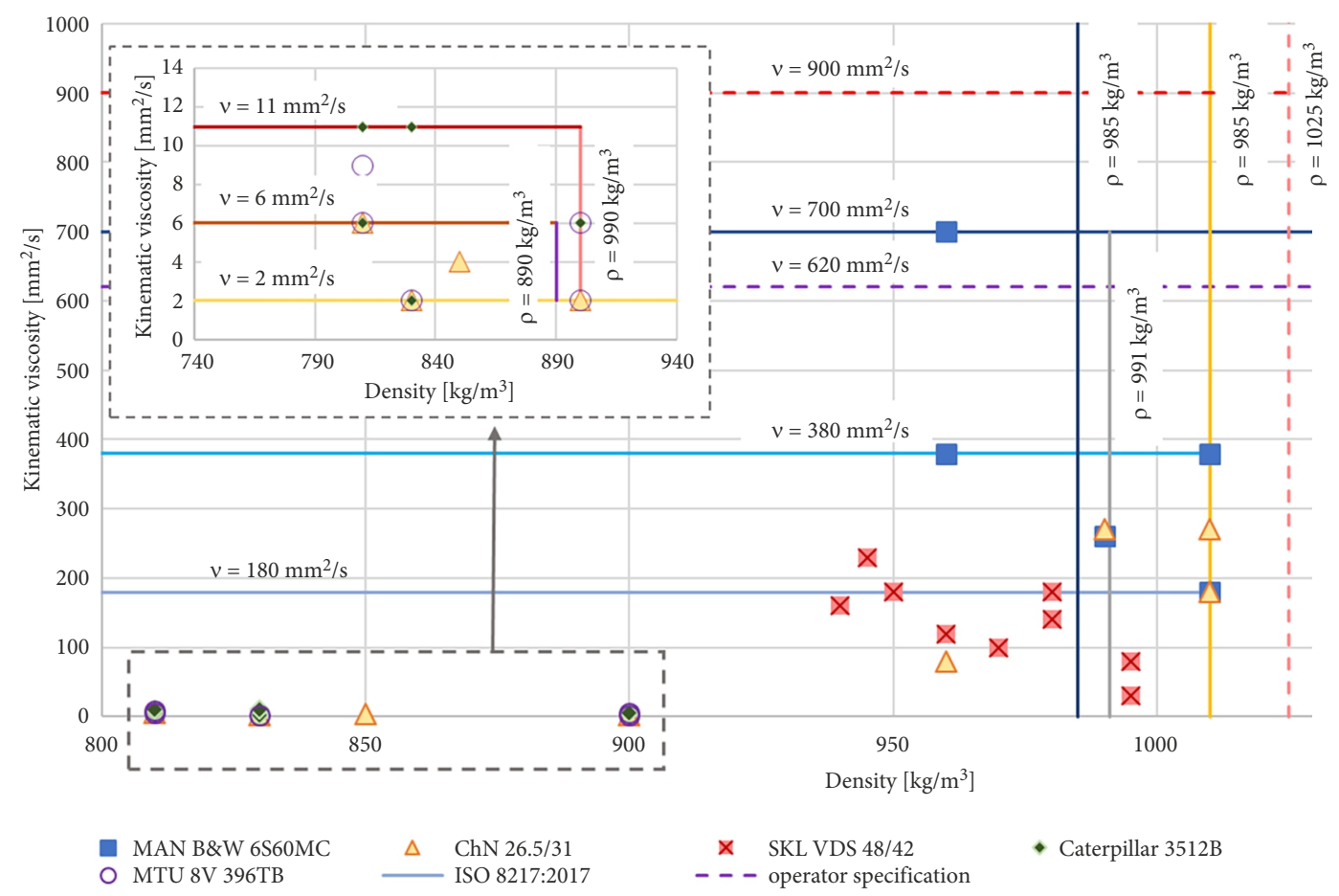

Figure 1. Parameters of selected fuel for engine modelling process

Table 1. Parameters of researched engines

\begin{tabular}{|c|c|c|c|c|c|}
\hline \multirow[b]{2}{*}{ Parameter } & \multicolumn{5}{|c|}{ Engine } \\
\hline & $\begin{array}{c}\text { MAN B\&W 6S60MC } \\
\text { (Denmark) }\end{array}$ & $\begin{array}{l}\text { ChN 26.5/31 } \\
\text { (Russia) }\end{array}$ & $\begin{array}{l}\text { SKL VDS } 48 / 42 \\
\text { (Germany) }\end{array}$ & $\begin{array}{l}\text { Caterpillar } \\
\text { 3512B (US) }\end{array}$ & $\begin{array}{c}\text { MTU 8V 396TB } \\
\text { (Germany) }\end{array}$ \\
\hline Classification by speed & low-speed & medium-speed & medium-speed & high-speed & high-speed \\
\hline Power [kW] & 13530 & 331 & 2650 & 1700 & 2150 \\
\hline Stroke & 2 & 4 & 4 & 4 & 4 \\
\hline Engine crankshaft speed $\left[\mathrm{min}^{-1}\right]$ & 105 & 1000 & 500 & 1800 & 2000 \\
\hline Number of cylinders & 6 & 1 & 6 & 12 & 16 \\
\hline Cylinder diameter [mm] & 600 & 265 & 420 & 170 & 165 \\
\hline Piston stroke [mm] & 2292 & 310 & 480 & 215 & 185 \\
\hline Compression ratio & 13.5 & 12.5 & 12.5 & 15.5 & 18.1 \\
\hline Fuel system type & CDS & CR & CDS & $\mathrm{CR}$ & CDS \\
\hline Fuel type & $\mathrm{RMF} / \mathrm{MDO}$ & $\mathrm{RMF} / \mathrm{MDO}$ & $\mathrm{RMF} / \mathrm{MDO}$ & MDO & MDO \\
\hline
\end{tabular}

The use of single-zone MMs is determined by the intended research strategy. Multi-dimensional MM are preferred among numerical models. When implemented in software packages, multi-dimensional MMs are effective at solving systems of moment (Navje-Stokes), energy (Furje-Kirghof), and mass-endurance equations - e.g., FIRE, KIVA and VECTIS. Based on MM benchmarking sources, one of the most common is the CFD model. Despite the advantages of multi-dimensional MM, their use at the preliminary estimates and prognosis stage is hampered by the lack of technical data of the study object necessary for reliable modelling.

These circumstances become the basis for the use of single-zone MMs of in the research, with limited technical information on the different types of operated ship power plants.
The IMPULS software that implements the MM performs closed modelling of the DE operating process, model on closed diesel cycle with turbo-compressor. Modelling is based on quasi-static thermodynamic and gas dynamic equations with regards to exhaust system influence, changes in turbo-compressor efficiency, heat loss, and ambient temperature and pressure. The work processes in the engine cylinder are described by a system consisting of the first law of thermodynamics, law of mass retention, and state equations.

The Diesel-RK MM used in the research, is based on the model of N. F. Razlejcev, modified by A. S. Kuleshov. The calculation of the working mixture formation and combustion characteristics in the DE cylinder was performed in steps of $0.2 \ldots 1{ }^{\circ}$ c.r.a (Kuleshov 2004). 
To ensure the adequacy of the numerical investigations, the MM matching was performed in different engine operating modes: propulsion, external speed, and load (at nominal and partial DE crankshaft speeds). The example in Figure 2 illustrates the high-speed diesel engine Caterpillar 3512B series (operating according to propulsive characteristics), while Figure 3 presents comparative data fragments of the average speed SKL VDS $48 / 42$ diesel engine (operating according to load characteristics at nominal speeds) and the numerical modelling.

In general, the numerical modelling accuracy is characterised by the error between the MM result and the experimental data, not exceeding $2 \ldots 7 \%$, according to the main DE parameters $\left(b_{e}, P_{\max }, T_{t}, P_{k}\right.$, etc. $)$. A summary of the results of the MM matching with the research objects is provided in the Appendix A.

Higher calorific value was evaluated according to the ISO 8217:2017 standard:

$$
\begin{aligned}
& H_{u}=\left(46.704-8.802 \rho_{15}^{2} \cdot 10^{-6}+\right. \\
& \left.3.167 \rho_{15} \cdot 10^{-3}\right) \cdot\left(1-0.01 \cdot\left(w_{w}+w_{a}+w_{s}\right)\right)+ \\
& 0.0942 \cdot w_{s}-0.024 \cdot w_{w} .
\end{aligned}
$$

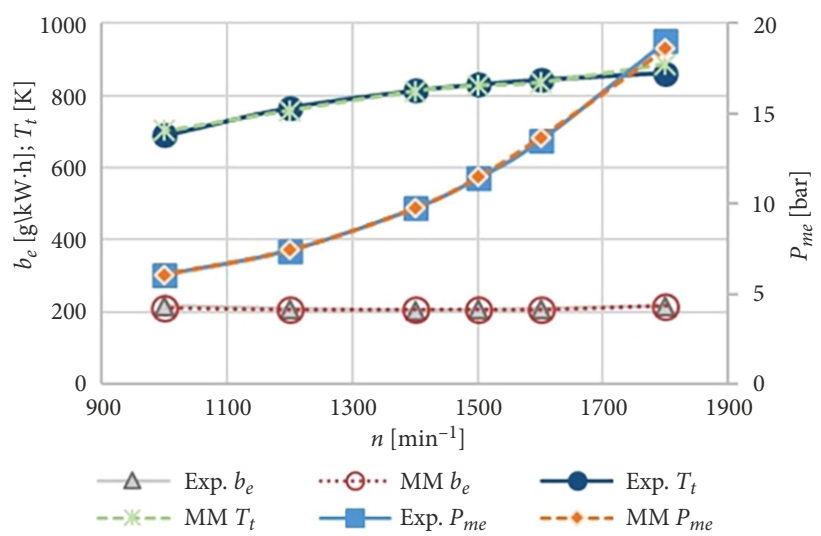

Figure 2. Caterpillar 3512B experimental data and MM specific fuel consumption $b_{e}$, exhaust gas temperature $T$, and mean effective pressure $P_{m e}$ readings

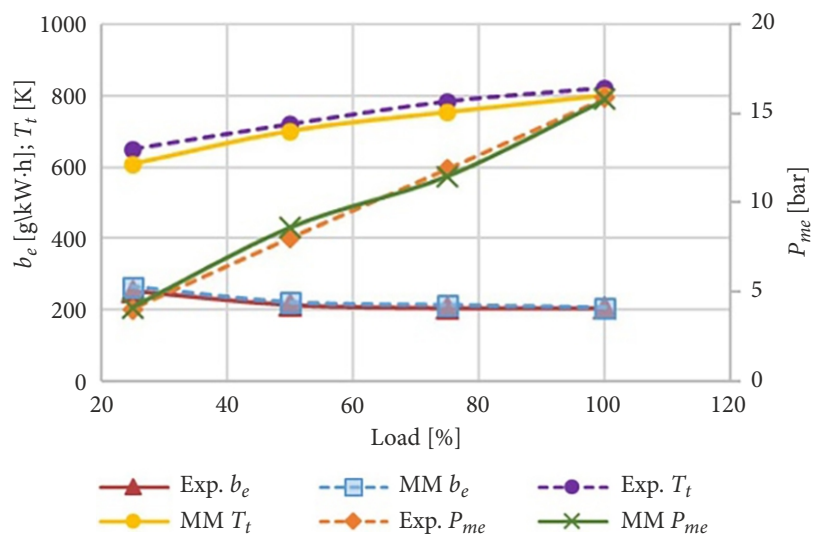

Figure 3. SKL VDS 48/42 experimental data and MM specific fuel consumption $b_{e}$, exhaust gas temperature $T$, and mean effective pressure $P_{m e}$ readings
The wide range of MBF density and viscosity combinations determines the engine workflow variations, which, in turn, include energy, ecological, and reliability parameters. The combustibility period changes, and primarily depends on the fuel activation energy and heat capacity changes, which change the engine power output and energy efficiency indicators. Moreover, the fuel bulk modulus changes, influencing the actual fuel injection angle in conventional systems. These DE energy efficiency influencing parameters are not defined and limited in MBF standards. Therefore, when the MBF standardised $\rho$ and $v$ properties change, for example, compared to previous DE MBF types, no measures exist for assessing the expected changes in the DE energy parameters.

The rational selection of MBF properties could be based on the mathematical modelling of DE parameter changes or factographic data for a particular DE type.

\section{Results and discussion}

In numerous MMs, the activation energy $E_{a}$ and $\mathrm{CN}$ (Lakshminarayanan, Aghav 2010; Abbe et al. 2013; Tuti et al. 2017) are used to describe the fuel combustibility properties. MBF standards use the CCAI for the evaluation of combustibility properties and the $\mathrm{CI}$ for distillates.

Therefore, for the purpose of obtaining input data for modelling of DE operations on heavy fuels, the first stage was determination of a relationship between the CCAI and CN (Figure 4) based on literature sources and statistical data (Armas et al. 2012; Centeno-González et al. 2013; Shuverov et al. 2015).

The determination coefficient of the resulting linear graphical dependence $R^{2}=0.818$ testifies to the "strong" relationship between CCAI and CN.

In the second stage, the link between $E_{a}$ and $\mathrm{CN}$ was determined based on the variation modelling of the $\mathrm{DE}$ working process, using the multizone model Diesel-RK (Kuleshov 2004).

In the MM, based on analytical expression (Equation (3)) of the ignition delay period $\tau_{i}$, variation of $\tau_{i}$ was performed in two manners: (1) at $E_{a}=$ const, $C N=$ var and (2) at $E_{a}=$ var, $C N=$ const (Figure 5):

$$
\begin{gathered}
\tau_{i}=3.8 \cdot 10^{-6} \cdot\left(1-1.6 \cdot 10^{-4} \cdot n\right) \times \\
\sqrt{\frac{T_{f i}}{P_{f i}}} \cdot \exp \left(\frac{E_{a}}{R \cdot T_{f i}} \cdot \frac{70}{C N+25}\right) .
\end{gathered}
$$

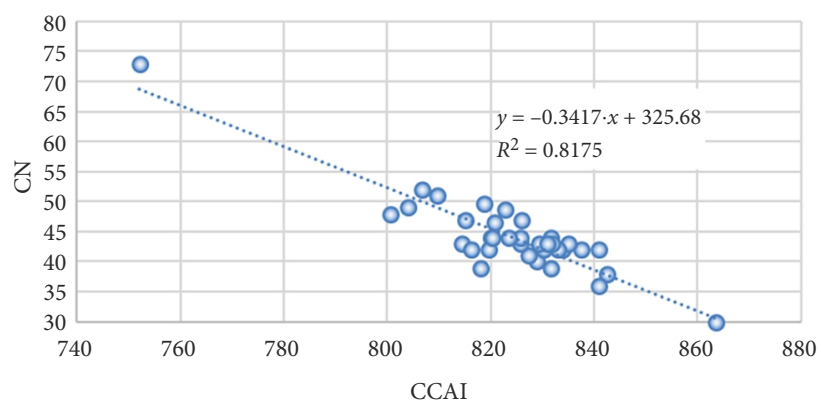

Figure 4. Relationship between CN and CCAI 
The $E_{a}$ and $C N$ values were calculated for every trend, where $\tau_{i}$ changed from 6 to 30 [ ${ }^{\circ}$ c.r.a]. For every combination, a dependency between $E_{a}$ and $C N$ over the matched ignition delay period $\tau_{i E_{a}}=\tau_{i C N}$ was determined (Figure 6a). For further calculations, based on the real $C N$ and $E_{a}$ correlation statistics (Zheng et al. 2013), the $C N_{E_{a} 30}-E_{a C N 45}$ dependence was selected (Figure 6b). The result is the proposed $E_{a}$ determination for heavy MBF based on the $\rho$ and $v$ properties, using the $C N=-0.3417 \cdot C C A I+325.68$ and $E_{a}=-0.4013 \cdot C N+48.26$ dependencies (Figure 6). The $E_{a}=f(C N)$ graphical dependency is used for the distillate MBF.

A change in the fuel injection angle is typical for a DE with a CDS. When fuel type is changed, the actual fuel injection angle changes owing to the different fuel bulk modulus. As the density increases, the actual fuel injection angle occurs earlier, which consequently has a negative impact on the DE performance. In order to assess the change in the injection angle, it is necessary to establish the relationship between the density regulated by the standard and the actual injection angle. For this purpose, based on the literature, a broad array of data on the density and corresponding bulk modulus of $\mathrm{HC}$ groups at $100{ }^{\circ} \mathrm{C}$ was formed (Tat et al. 2000; Tat, Van Gerpen 2003; Monyem et al. 2001; Han et al. 2017). Following data processing between the MBF density and fuel bulk modulus $B$, a linear correlation with a high determination coefficient of $R^{2}=0.944$ was determined (Figure 7).

a)

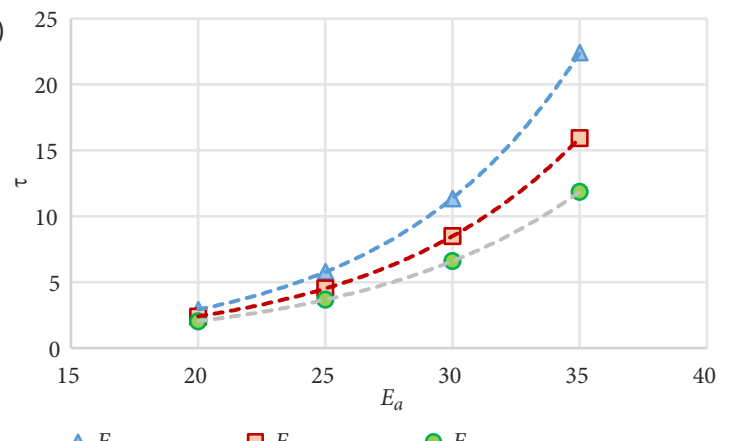

The actual fuel injection angle $\varphi_{i n j}$ is determined by fuel supply system design peculiarities, which are difficult to evaluate quantitatively and angle of fuel supply start by the pump, and therefore, a relative change of fuel injection angle evaluation was conducted, depending only on the fuel properties. The fuel injection delay angle $\Delta \varphi_{i n j}$ [ ${ }^{\circ}$ c.r.a] (the crankshaft angle interval between the fuel supply start by the pump and fuel injection into the engine cylinder) can be calculated by the Equation (4), therefore the injection delay angle is inversely proportional to the bulk modulus of used fuel (Tat, Van Gerpen 2003). A relative change in the fuel bulk modulus $\left(K=B_{1} / B_{2}\right)$ caused a relative change in the fuel injection delay angle $\left(\Delta \varphi_{i n j 2}=\Delta \varphi_{i n j 1} \cdot K\right)$; on this basis, the actual fuel injection angle $\varphi_{i n j}$ could be calculated.

$$
\Delta \varphi_{i n j}=\frac{\left(N O P-P_{0}\right) \cdot V_{f}}{B \cdot v_{\varphi} \cdot A_{p}},
$$

where: $\Delta \varphi_{i n j}$ is crankshaft angle interval between the fuel supply start by the pump and fuel injection into the engine cylinder [ ${ }^{\circ}$ c.r.a].

Based on the determined analytical solutions $E_{a}=f(\rho, v), \Delta \varphi_{i n j}=f(\rho), H_{u}=f(\rho)-($ ISO 8217:2017), mathematical modelling research on the influence of the MBF properties $\rho$ and $v$ on the DE energy parameters was performed. The value ranges of $\rho$ and $v$ were selected according to the analysed DE manufacturer regulations.

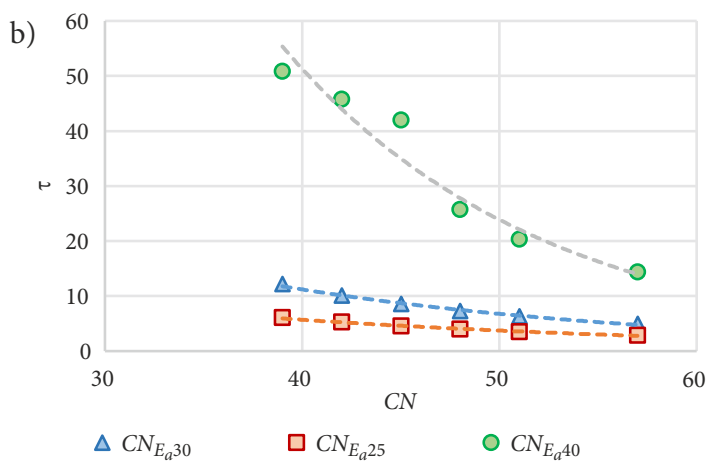

Figure 5. Ignition delay period depending on: $\mathrm{a}-E_{a} ; \mathrm{b}-C N$

a)

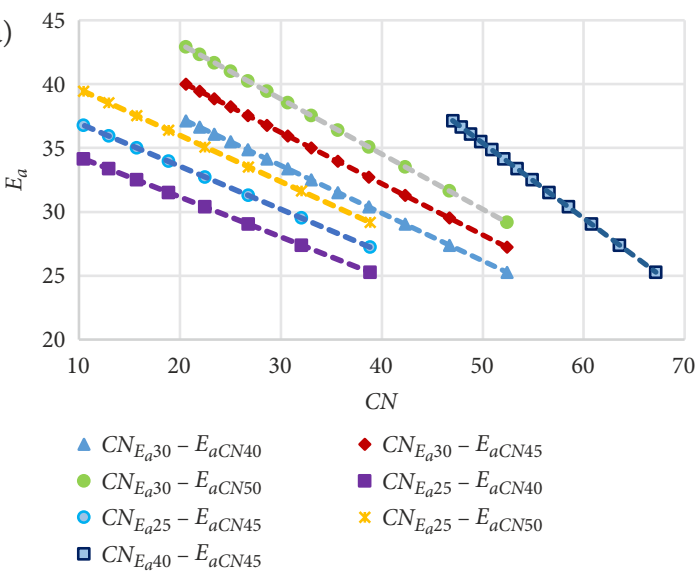

b)

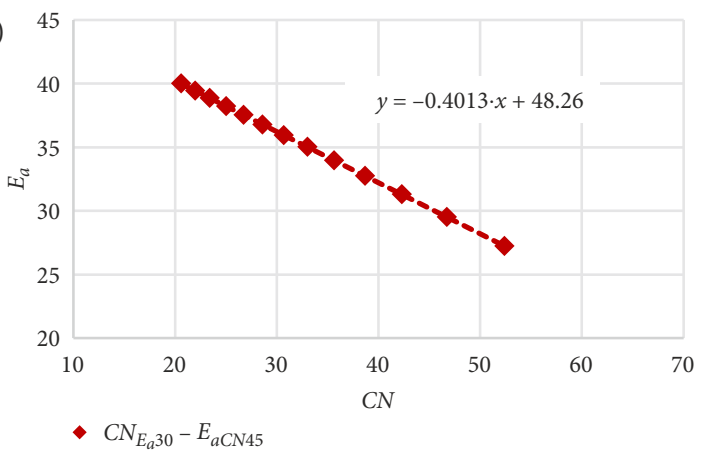

Figure 6. Relationship between $C N$ and $E_{a}: \mathrm{a}-C N$ and $E_{a}$ variation; b - selected relationship between $C N$ and $E_{a}$ 


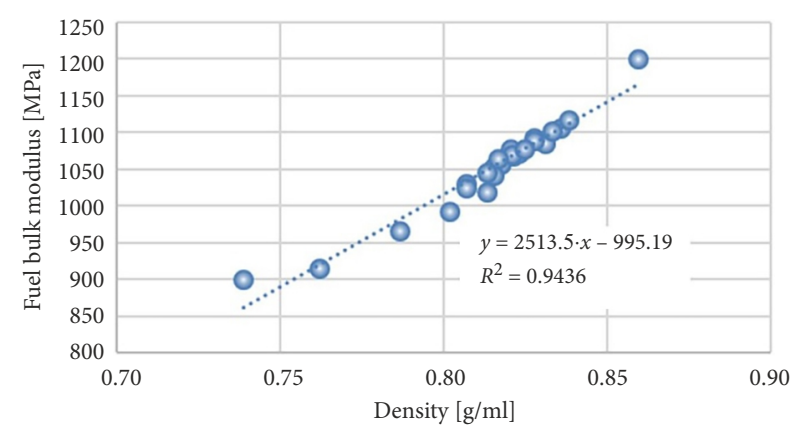

Figure 7. Relationship between density and bulk modulus

Modelling was conducted for nominal and partial loads of different propulsion plants, with a wide range of speed and load characteristics: according to the propulsion, load, and external speed-propeller).

Fragments of the modelling results for selected combinations of $\rho$ and $v$ for the high-speed diesel engine MTU 8V 396TB series, medium-speed diesel engine ChN 26.5/31 series, and low-speed diesel engine MAN B\&W 6 S60MC series engines are provided in the Appendix B. According to Equation (2), as the density increases, the calorific value of the fuel decreases, and the relative fuel consumption increases accordingly. The higher density, based on the dependence shown in Figure 7, correlates with the decrease of the fuel elasticity modulus and shorter injection delay, resulting in an earlier injection. With lower activation energy, ignition delay is also shorter - Equation (3). As a result, the fuel ignites earlier, which affects the entire combustion process. For example in case of MAN B\&W 6S60MC engine, when comparing fuel types, fuel with $\rho=960 \mathrm{~kg} / \mathrm{m}^{3} ; v=700 \mathrm{~mm}^{2} / \mathrm{s}$ causes $4.0 \ldots 5.9 \%$ lower relative fuel consumption than fuel with $\rho=1010 \mathrm{~kg} / \mathrm{m}^{3} ; v=180 \mathrm{~mm}^{2} / \mathrm{s}$ in highest and medium load respectively. The ignition delay in both cases is $65 \%$ shorter.
Based on the percentage change in specific fuel consumption $b_{e}$, equations for $b_{e}$ changes by density and viscosity with a determination coefficient of 0.99 , established in the graphs form, are obtained. For convenience, both dependencies on conversion factors $\left(\beta_{i}\right.$ and $\left.\gamma_{i}\right)$ are transformed into one $b_{e}$ prediction equation:

$$
b_{e 2}=b_{e 1} \cdot\left(1+\frac{\gamma_{2}-\gamma_{1}}{100}+\frac{\beta_{2}-\beta_{1}}{100}\right) \text {. }
$$

Depending on density and viscosity, the obtained coefficients allow predicting specific fuel consumption for individual DE types. The variance of the specific fuel consumption ratio for the MAN B\&W 6S60MC engine (maximum load) from the base fuel (accepted for 1) is shown in Table 2. Rectangular marked values are obtained by modelling. A darker background indicates a higher value for specific fuel consumption.

The obtained results confirm the above-mentioned influence of the qualitative $\rho$ and $v$ values on the DE work process and energy efficiency parameters. A combination of maximum viscosity and minimum density is the most suitable for DE energy efficiency improvement. The summarised mathematical modelling results with a margin of error up to $1 \%$ to $2 \%$ are presented as factographic data in Figures 8 to 13.

The provided results aid in evaluating numerous common influences of $\rho$ and $v$ on all DE types. The changes in the analysed energy efficiency parameters are primarily owing to the influence of the MBF density. The MBF viscosity influence is more eminent in low-density cases, and only with a low viscosity value change. The change in the BSFC in the $\rho-v$ field, from minimal $\rho$ values to 1000 to $1010 \mathrm{~kg} / \mathrm{m}^{3}$, is $3 \%$ to $4 \%$. In cases of increased density up to $1030 \mathrm{~kg} / \mathrm{m}^{3}$ at minimal $v$ values, the low-speed engine BSFC intensively increases by an additional 5\% (Figure 8).

Table 2. MAN B\&W 6S60MC engine specific fuel consumption at full load relative change matrix in the $\rho-v$ field

\begin{tabular}{|c|c|c|c|c|c|c|c|c|c|c|}
\hline \multirow{4}{*}{$\beta$} & \multirow{4}{*}{$v\left[\mathrm{~mm}^{2} / \mathrm{s}\right]$} & \multicolumn{9}{|c|}{$\gamma$} \\
\hline & & 0.00 & 0.01 & 0.03 & 0.36 & 1.07 & 2.12 & 3.51 & 5.21 & 7.17 \\
\hline & & \multicolumn{9}{|c|}{ Density $\left[\mathrm{kg} / \mathrm{m}^{3}\right]$} \\
\hline & & 950 & 960 & 970 & 980 & 990 & 1000 & 1010 & 1020 & 1030 \\
\hline 0.005 & 710 & 0.9827 & 0.9828 & 0.9834 & 0.9864 & 0.9934 & 1.0043 & 1.0172 & 1.0341 & 1.0540 \\
\hline 0.013 & 700 & 0.9828 & 0.9870 & 0.9835 & 0.9865 & 0.9934 & 1.0044 & 1.0173 & 1.0342 & 1.0540 \\
\hline 0.021 & 690 & 0.9829 & 0.9830 & 0.9836 & 0.9866 & 0.9935 & 1.0045 & 1.0174 & 1.0343 & 1.0541 \\
\hline 0.361 & 390 & 0.9863 & 0.9864 & 0.9870 & 0.9899 & 0.9969 & 1.0079 & 1.0209 & 1.0378 & 1.0577 \\
\hline 0.378 & 380 & 0.9864 & 0.9870 & 0.9871 & 0.9901 & 0.9971 & 1.0081 & 1.0220 & 1.0380 & 1.0579 \\
\hline 0.415 & 360 & 0.9868 & 0.9869 & 0.9875 & 0.9905 & 0.9975 & 1.0084 & 1.0214 & 1.0384 & 1.0583 \\
\hline 0.635 & 270 & 0.9890 & 0.9891 & 0.9897 & 0.9927 & 0.9997 & 1.0107 & 1.0237 & 1.0407 & 1.0607 \\
\hline 0.668 & 260 & 0.9893 & 0.9894 & 0.9896 & 0.9929 & 1.0000 & 1.0105 & 1.0244 & 1.0414 & 1.0610 \\
\hline 0.740 & 240 & 0.9900 & 0.9901 & 0.9907 & 0.9937 & 1.0007 & 1.0117 & 1.0247 & 1.0417 & 1.0618 \\
\hline 0.870 & 210 & 0.9913 & 0.9914 & 0.9920 & 0.9950 & 1.0020 & 1.0130 & 1.0261 & 1.0431 & 1.0631 \\
\hline 1.041 & 180 & 0.9930 & 0.9931 & 0.9937 & 0.9967 & 1.0037 & 1.0148 & 1.0280 & 1.0449 & 1.0650 \\
\hline 2.469 & 80 & 1.0071 & 1.0072 & 1.0078 & 1.0109 & 1.0180 & 1.0292 & 1.0424 & 1.0597 & 1.0801 \\
\hline
\end{tabular}


Therefore, in operation, fuels with $\rho>1000$ to $1010 \mathrm{~kg} / \mathrm{m}^{3}$ and $v<300$ to $400 \mathrm{~mm}^{2} / \mathrm{s}$ should be avoided.

DEs operating on a wide range of MBFs are more "sensitive" to light fuel fraction $\rho$ and $v$ changes. This correlates strongly with statistical data from CIMAC. For example, for the diesel engine $\mathrm{ChN} 26.5 / 31$ operating on heavy

a)

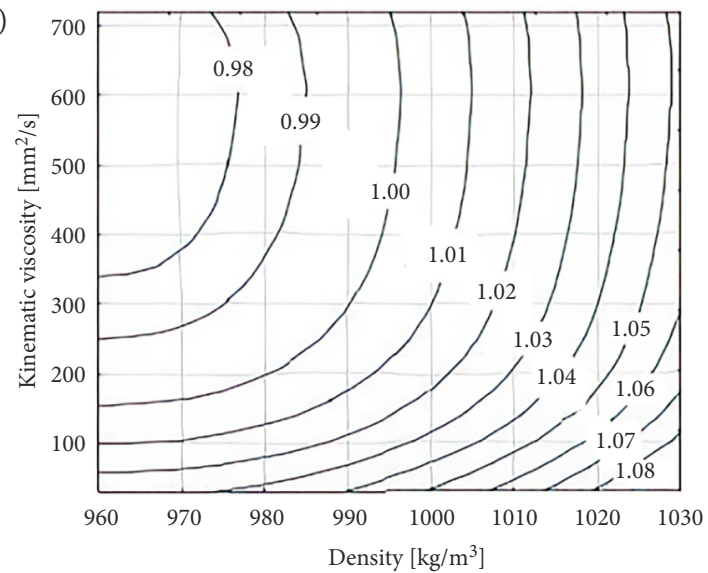

MBF (RMG 180 - RMK 380 ISO 8217:2017), the change in the BSFC in the standard regulated $\rho-v$ field does not exceed 3\% (Figure 10), while during the operation of light MBF (DMA - DMB), the BSFC change reaches from 7 to $11 \%$ (Figure 9). We also see in Figures 11 and 12 that as fuel density increases and viscosity decreases, fuel con-

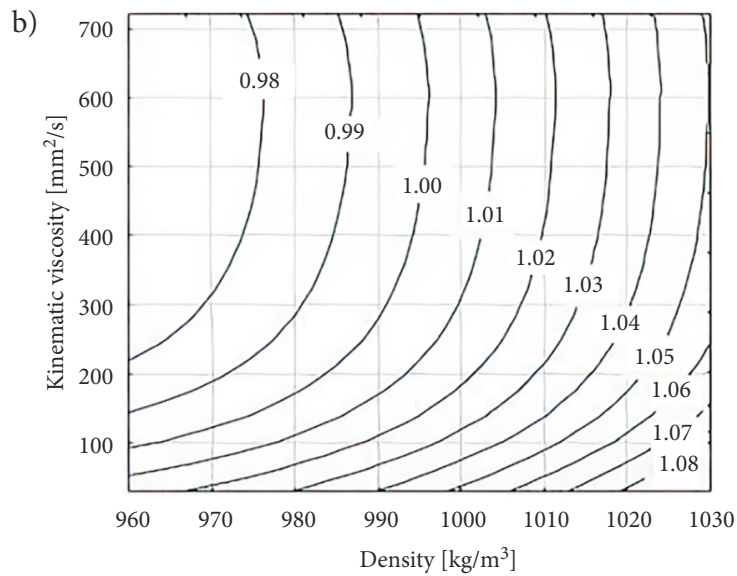

Figure 8. Multivariate characteristics of relative BSFC change in MAN B\&W 6S60MC engine: a - full load; b - partial load

a)

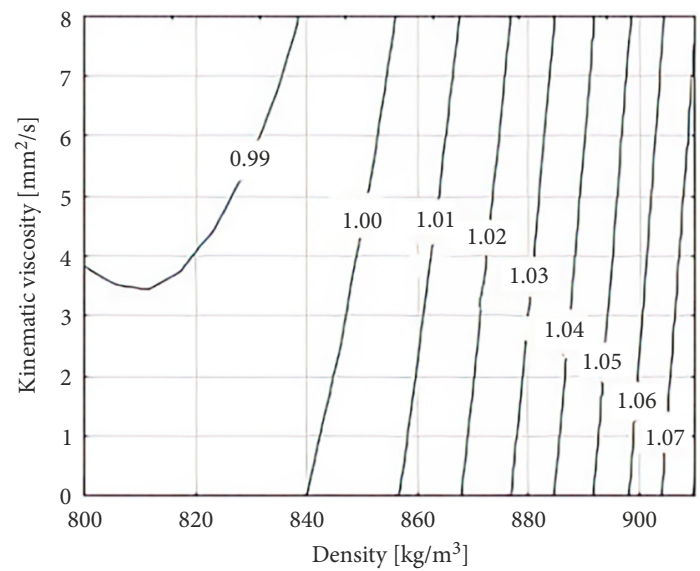

b)

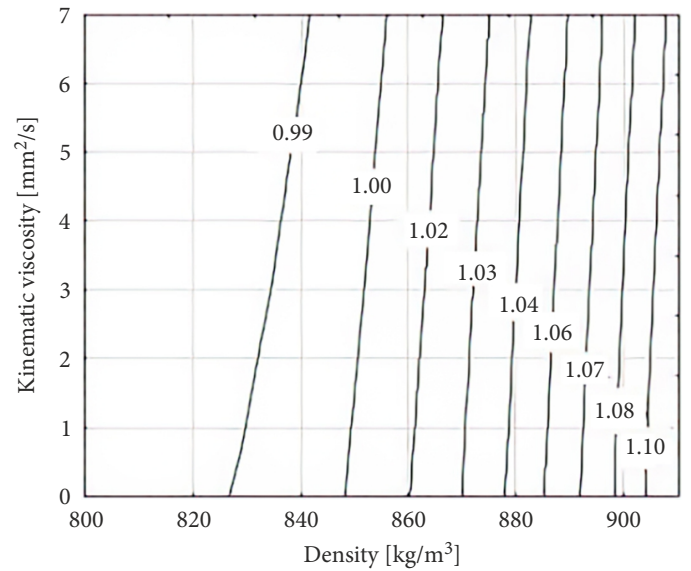

Figure 9. Multivariate characteristics of relative BSFC change in ChN 26.5/31 engine working with diesel: a - full load; b - partial load

a)

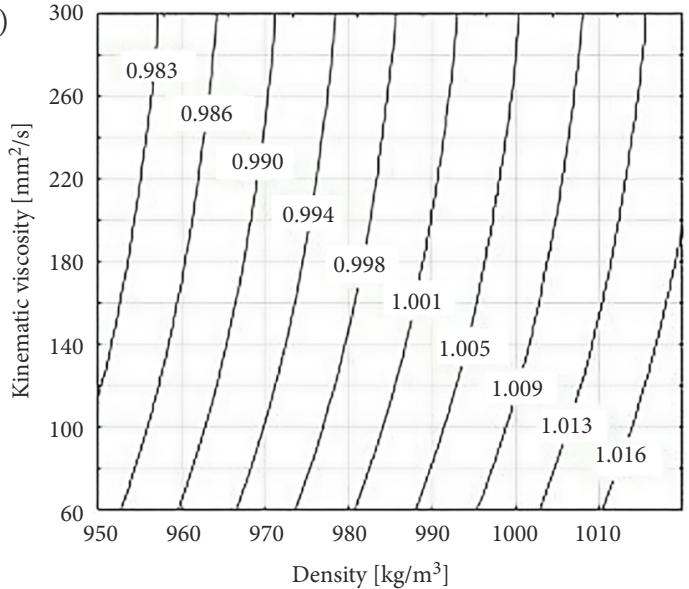

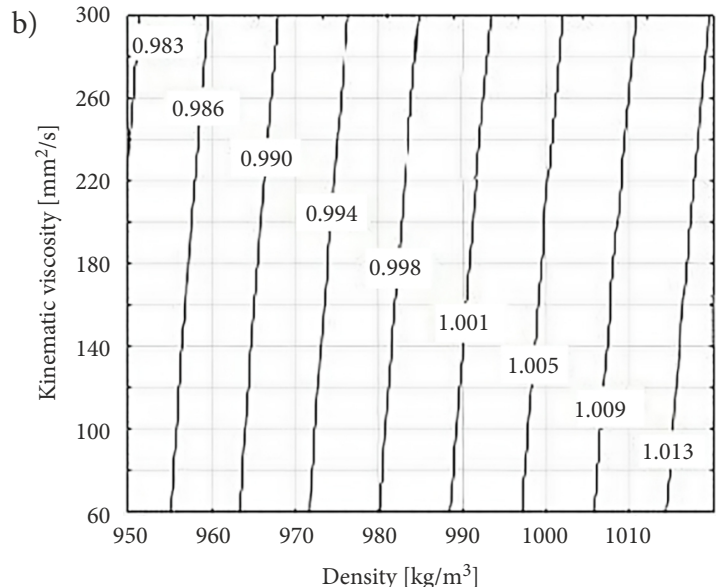

Figure 10. Multivariate characteristics of relative BSFC change in ChN 26.5/31 engine working with residual fuel: a - full load; b - partial load 
sumption increases. Overall, the available changes in fuel consumption, that can be achieved by provided method can range of $2 \ldots 7 \%$ and in some cases up to $10 \%$. This is comparable to some of other methods, used for reduction of fuel consumption for ships, such as changes in hull and propulsion plant design, additional waste heat recovery, change of fuel type and energy management (Lassesson, Andersson 2009; Yan et al. 2020). Fuel consumption prediction and optimisation models usually involve evaluation of multiple parameters including hull resistance, weather influence, currents, engine load and many others and by selecting optimal speed, course and load can reach
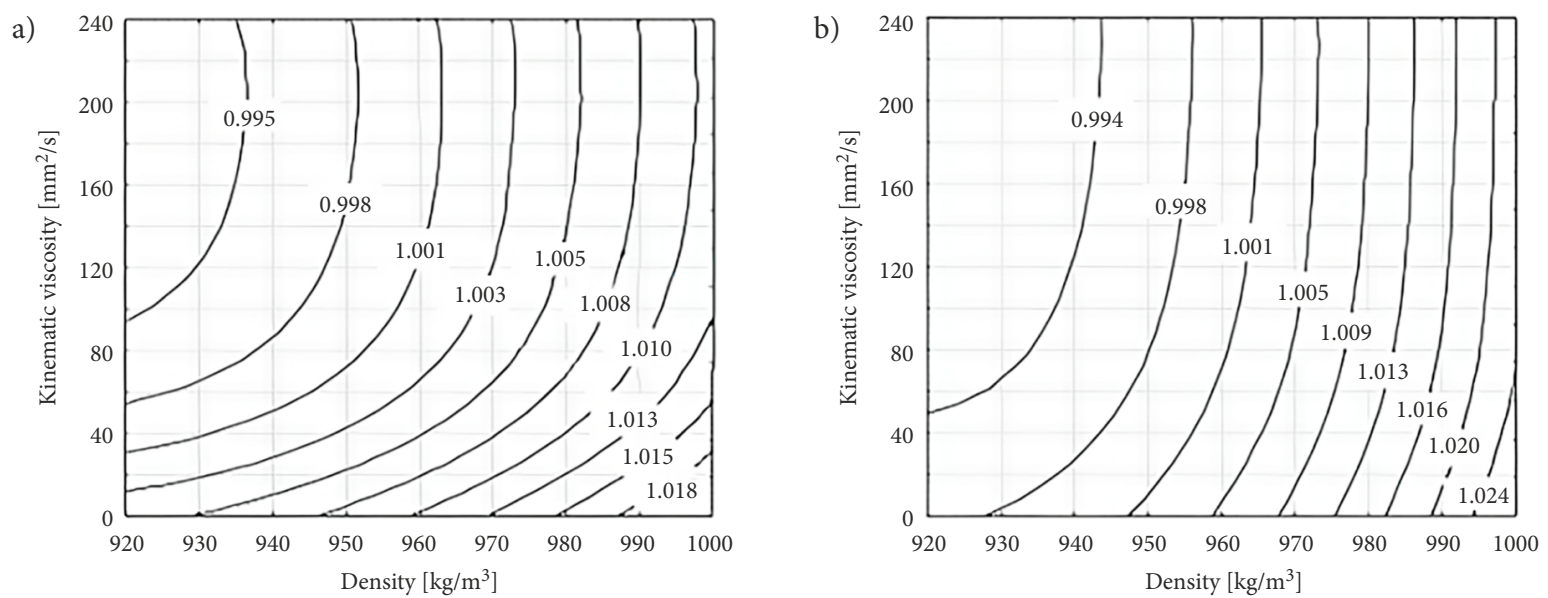

Figure 11. Multivariate characteristics of relative BSFC change in SKL VDS 48/42 engine: a - full load; b - partial load

a)

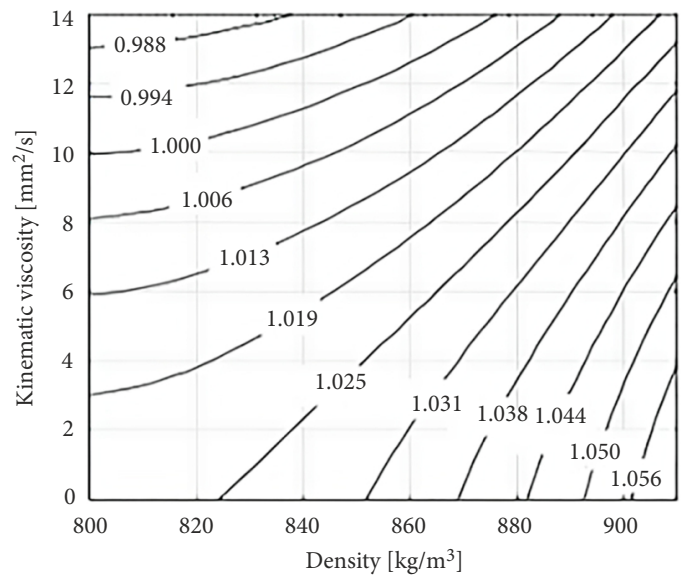

b)

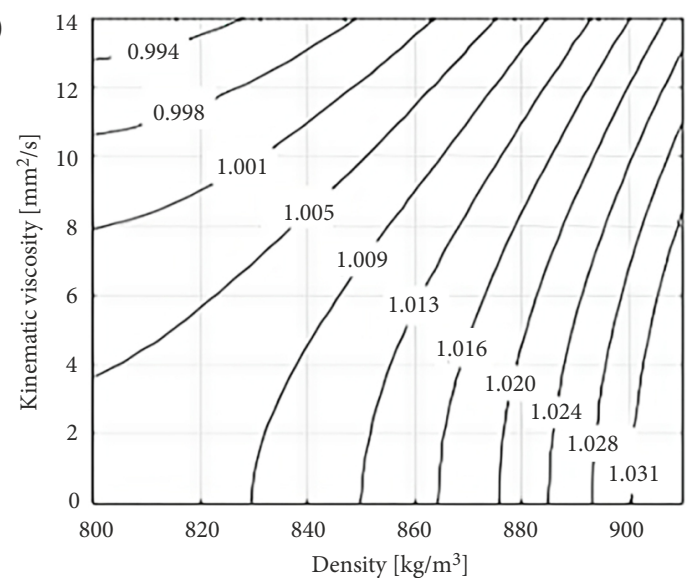

Figure 12. Multivariate characteristics of relative BSFC change in Caterpillar 3512B engine: a - full load; b - partial load

a)

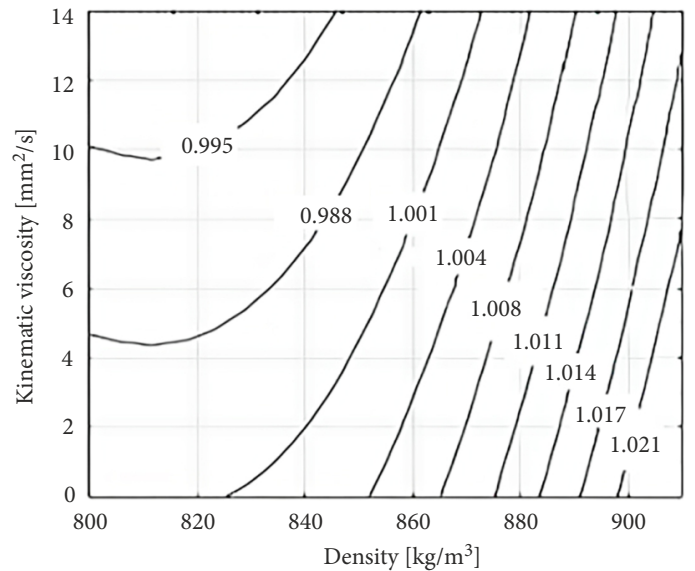

b)

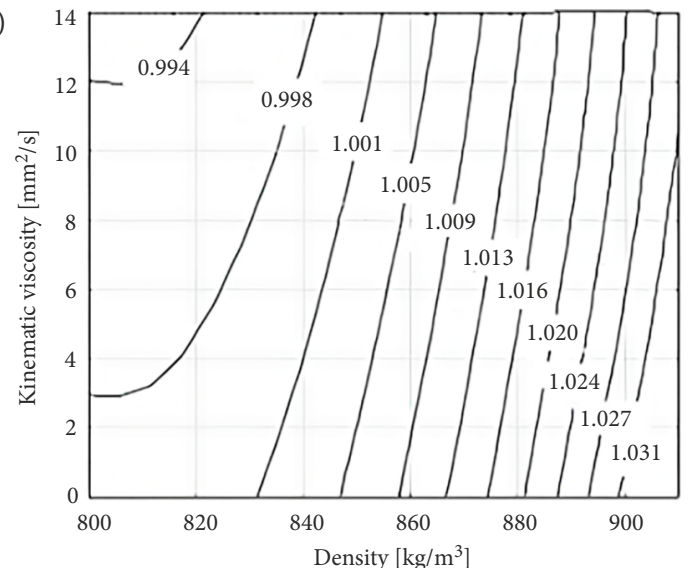

Figure 13. Multivariate characteristics of relative BSFC change in MTU 8V 396TB engine: a - full load; b - partial load 
up to $2 \ldots 7 \%$ in fuel consumption reduction (Panapakidis et al. 2020; Yan et al. 2020; Kim et al. 2021; Moreira et al. 2021). But in very few it is noted, that fuel quality parameters also influence efficiency and that the effect can be different for each engine model, as it was also shown in this study (Lundh et al. 2016; Panapakidis et al. 2020). The fuel quality influence, estimated by other researchers were from less than 1\% (Zannis et al. 2007) to 2\% (Lundh et al. 2016). In both estimations, it should be noted that analysis was limited by only one engine model and small spectra of fuel properties. With greater variations of fuels analysed, even higher reductions can be achieved. It is also shown by Panapakidis et al. (2020) that even though fuel quality parameters are important factor in fuel consumption prediction there are no concrete tools for estimation of quantitative influence of the properties of a wide range of marine fuels on the energy performance of ship power plants. It is there for important to have tool, like the proposed method, that can be easily integrated in the ship fuel economy prediction models.

The proposed method also has some drawbacks and assumptions that can influence application:

"'» in evaluation it assumed that data on fuel properties provided in fuel certificate are correct, but as noted by Anfindsen et al. (2012), that fuel certificates might not always be sufficiently accurate. Ideally a separate laboratory analysis of every new bunker should be performed;

"») effect of fuel degradation is not considered in evaluation;

"') the reduction of fuel consumption depends on the engine model and can prove to have little effect in some cases, further research on different engines is necessary to improve accuracy of the prediction.

Authors plan to extend the research to a wider range of marine fuels and investigating the impact on reliability indicators in future works.

\section{Conclusions}

The aim of work is to form a methodological framework for assessing the influence of marine fuel properties on the energy performance of different types of ship power plants. Proposed methodology evaluates fuel injection phase delay with increasing viscosity of marine fuels (share of aromatic HCs groups in marine fuels); decrease in activation energy and net calorific value of marine fuels with increasing density (share of paraffinic HC groups in marine fuels) and their influence on engine parameters and fuel efficiency. Evaluations are provided for all major types of marine engines with different engine models of low, medium and high-speed, with greatest influence determined for the low-speed and least for high-speed engines. Unfavourable combination of fuel density and viscosity, that can have negative impact of fuel consumption have also been established. In quantitative terms the influence of $\mathrm{MBF}$ properties on the comparative fuel consumption of the main types of marine DEs:

"» low-speed diesel engine MAN B\&W 6S60MC comparative BSFC increase up to $10 \%$;

"» for medium-speed diesel engines SKL VDS 48/42 and $\mathrm{ChN}$ 26.5/31 comparative BSFC increased by 3...7\%;

"» high-speed diesel engines Caterpillar 3512B and MTU 8V 396TB models comparative BSFC change averaged at $2 . .3 \%$.

For the rational selection of marine fuel properties for a specific DE model, performed complex laboratory and MM tests and on their basis - methodological solutions are proposed that evaluate the influence of density and viscosity on the characteristics of the engine indicator process in factographic form. Provided method also adds fuel quality influence as a variable in moderns ship fuel consumption prediction models that currently lack this feature. This will improve engine fuel consumption prediction models and also provides clarity and important information for $\mathrm{MBF}$ selection process and $\mathrm{CO}_{2}$ reduction.

\section{Author contributions}

Sergejus Lebedevas and Nadežda Lazareva - main contributing authors of the publication, making of the first drafts as well as editing.

Paulius Rapalis and Vygintas Daukšys - editing and reviewing of draft, providing insights and additions to different sections as well as translation.

Tomas Čepaitis - responsible for editing and improving literature review as well as contributing to other section of publication. 


\section{Appendix A: model matching}

Table A1. Comparison of diesel engine Caterpillar 3512B MM adequacy validation experiment and modelling results

\begin{tabular}{|c|c|c|c|c|c|c|c|c|c|c|}
\hline \multirow{2}{*}{$n\left[\mathrm{~min}^{-1}\right]$} & \multicolumn{2}{|c|}{$P_{m e}[\mathrm{bar}]$} & \multicolumn{2}{|c|}{$b_{e}[\mathrm{~g} / \mathrm{kW} \cdot \mathrm{h}]$} & \multicolumn{2}{c|}{$T_{t}[\mathrm{~K}]$} & \multicolumn{2}{c|}{$\alpha[-]$} & \multicolumn{2}{c|}{$P_{k}[\mathrm{bar}]$} \\
\cline { 2 - 12 } & Experimental & $\mathrm{MM}$ & Experimental & $\mathrm{MM}$ & Experimental & $\mathrm{MM}$ & Experimental & MM & Experimental & MM \\
\hline 1800 & 19.00 & 18.60 & 216.8 & 217.1 & 862 & 886 & 2.00 & 2.07 & 3.60 & 3.70 \\
\hline 1600 & 13.50 & 13.70 & 209.0 & 208.5 & 843 & 836 & 2.04 & 2.00 & 2.40 & 2.40 \\
\hline 1500 & 11.40 & 11.47 & 206.0 & 209.0 & 830 & 827 & 2.03 & 1.97 & 2.00 & 1.95 \\
\hline 1400 & 9.74 & 9.77 & 205.0 & 208.6 & 814 & 812 & 1.95 & 1.97 & 1.63 & 1.64 \\
\hline 1200 & 7.40 & 7.43 & 209.0 & 208.5 & 767 & 759 & 2.00 & 2.11 & 1.27 & 1.30 \\
\hline 1000 & 6.05 & 6.08 & 217.0 & 212.5 & 691 & 702 & 2.21 & 2.28 & 1.18 & 1.16 \\
\hline
\end{tabular}

Table A2. Comparison of diesel engine MTU 8V 396TB MM adequacy validation experiment and modelling results

\begin{tabular}{|c|c|c|c|c|c|c|c|c|c|c|}
\hline \multirow{2}{*}{$n\left[\min ^{-1}\right]$} & \multicolumn{2}{|c|}{$P_{m e}[\mathrm{bar}]$} & \multicolumn{2}{|c|}{$b_{e}[\mathrm{~g} / \mathrm{kW} \cdot \mathrm{h}]$} & \multicolumn{2}{|c|}{$T_{t}[\mathrm{~K}]$} & \multicolumn{2}{|c|}{$\alpha[-]$} & \multicolumn{2}{|c|}{$P_{k}[$ bar $]$} \\
\hline & Experimental & $\mathrm{MM}$ & Experimental & $\mathrm{MM}$ & Experimental & MM & Experimental & $\mathrm{MM}$ & Experimental & $\mathrm{MM}$ \\
\hline 1850 & 12.30 & 12.30 & 212.0 & 211.0 & 913 & 895 & 1.83 & 1.75 & 0.210 & 0.212 \\
\hline 1650 & 13.90 & 13.90 & 204.0 & 204.6 & 923 & 941 & 1.65 & 1.59 & 0.207 & 0.209 \\
\hline 1400 & 10.01 & 10.05 & 204.5 & 204.0 & 863 & 888 & 1.67 & 1.60 & 0.153 & 0.151 \\
\hline 1100 & 6.16 & 6.16 & 211.7 & 212.6 & 738 & 740 & 1.93 & 1.96 & 0.116 & 0.117 \\
\hline
\end{tabular}

Table A3. Comparison of diesel engine SKL VDS 48/42 MM adequacy validation experiment and modelling results

\begin{tabular}{|c|c|c|c|c|c|c|c|c|c|c|}
\hline \multirow{2}{*}{ Load [\%] } & \multicolumn{2}{|c|}{$P_{m e}[$ bar $]$} & \multicolumn{2}{|c|}{$b_{e}[\mathrm{~g} / \mathrm{kW} \cdot \mathrm{h}]$} & \multicolumn{2}{|c|}{$T_{t}[\mathrm{~K}]$} & \multicolumn{2}{|c|}{$\alpha[-]$} & \multicolumn{2}{|c|}{$P_{k}[$ bar $]$} \\
\hline & Experimental & $\mathrm{MM}$ & Experimental & $\mathrm{MM}$ & Experimental & MM & Experimental & MM & Experimental & MM \\
\hline 100 & 15.9 & 15.8 & 205 & 205 & 822 & 800 & 1.95 & 2.08 & 2.62 & 2.60 \\
\hline 75 & 11.9 & 11.5 & 205 & 212 & 784 & 753 & 2.12 & 2.25 & 2.12 & 2.09 \\
\hline 50 & 8.0 & 8.6 & 214 & 220 & 720 & 700 & 2.44 & 2.47 & 1.73 & 1.77 \\
\hline 25 & 4.0 & 4.1 & 251 & 263 & 650 & 607 & 3.20 & 3.37 & 1.36 & 1.37 \\
\hline
\end{tabular}

Table A4. Comparison of diesel engine $\mathrm{ChN}$ 26.5/31 MM adequacy validation experiment and modelling results

\begin{tabular}{|c|c|c|c|c|c|c|}
\hline \multicolumn{7}{|c|}{$n=1000 \mathrm{~min}^{-1}$} \\
\hline \multirow{2}{*}{ Load [\%] } & \multicolumn{2}{|c|}{$P_{\max }[$ bar $]$} & \multicolumn{2}{|c|}{$b_{e}[\mathrm{~g} / \mathrm{kW} \cdot \mathrm{h}]$} & \multicolumn{2}{|c|}{$T_{t}[\mathrm{~K}]$} \\
\hline & Experimental & $\mathrm{MM}$ & Experimental & MM & Experimental & $\mathrm{MM}$ \\
\hline 50 & 136 & 134.2 & 214.69 & 213.3 & 740 & 772 \\
\hline 75 & 173 & 176.3 & 202.20 & 200.5 & 778 & 808 \\
\hline 100 & 195 & 193.2 & 204.80 & 207.2 & 884 & 866 \\
\hline 110 & 200 & 199.5 & 206.31 & 208.4 & 843 & 896 \\
\hline
\end{tabular}

Table A5. Comparison of diesel engine MAN B\&W 6S60MC MM adequacy validation experiment and modelling results

\begin{tabular}{|c|c|c|c|c|c|c|c|c|c|c|c|c|}
\hline \multicolumn{13}{|c|}{$n=500 \mathrm{~min}^{-1}$} \\
\hline \multirow{2}{*}{ Load [\%] } & \multicolumn{2}{|c|}{$P_{m e}[\mathrm{bar}]$} & \multicolumn{2}{|c|}{$b_{e}[\mathrm{~g} / \mathrm{kW} \cdot \mathrm{h}]$} & \multicolumn{2}{|c|}{$T_{t}[\mathrm{~K}]$} & \multicolumn{2}{|c|}{$P_{e}[\mathrm{~kW}]$} & \multicolumn{2}{|c|}{$P_{k}[$ bar $]$} & \multicolumn{2}{|c|}{$P_{\max }[\mathrm{bar}]$} \\
\hline & Exp. & MM & Exp. & MM & Exp. & MM & Exp. & MM & Exp. & MM & Exp. & MM \\
\hline 85 & 15.85 & 15.8 & 200.8 & 201.4 & 831 & 834 & 9553 & 9523 & 3.1 & 3.1 & 121.4 & 123.8 \\
\hline 75 & 14.52 & 14.8 & 204.5 & 200.6 & 825 & 862 & 8460 & 8623 & 2.9 & 2.8 & 111.9 & 116.2 \\
\hline 50 & 11.18 & 11.0 & 212.0 & 215.5 & 837 & 869 & 5638 & 5547 & 2.1 & 2.3 & 85.0 & 89.1 \\
\hline 25 & 7.32 & 7.4 & 218.7 & 215.2 & 836 & 876 & 2968 & 3017 & 1.4 & 1.5 & 66.0 & 70.7 \\
\hline
\end{tabular}




\section{Appendix B: modelling results}

Table B1. Influence of MBF properties on diesel engine MAN B\&W 6S60MC parameters

\begin{tabular}{|c|c|c|c|c|c|c|c|c|}
\hline \multirow{3}{*}{$\begin{array}{c}\text { Parameter } \\
\text { Make }\end{array}$} & \multicolumn{8}{|c|}{ Load } \\
\hline & \multicolumn{4}{|c|}{$100 \%$} & \multicolumn{4}{|c|}{$25 \%$} \\
\hline & RMG-700 & RMG-380 & RMK-380 & RMK-380 & RMG-700 & RMG-380 & RMK-380 & RMK-380 \\
\hline$\rho\left[\mathrm{kg} / \mathrm{m}^{3}\right]$ & 960 & 960 & 1010 & 1010 & 960 & 960 & 1010 & 1010 \\
\hline$v\left[\mathrm{~mm}^{2} / \mathrm{s}\right]$ & 700 & 380 & 380 & 180 & 700 & 380 & 380 & 180 \\
\hline$n\left[\min ^{-1}\right]$ & 105 & 105 & 105 & 105 & 66 & 66 & 66 & 66 \\
\hline$H_{u}[\mathrm{MJ} / \mathrm{kg}]$ & 41.63 & 41.63 & 40.92 & 40.92 & 41.63 & 41.63 & 40.92 & 40.92 \\
\hline$E_{a}[\mathrm{~kJ} / \mathrm{mol}]$ & 28.99 & 29.81 & 36.69 & 37.82 & 28.99 & 29.81 & 36.69 & 37.82 \\
\hline$\varphi_{i n j}\left[{ }^{\circ}\right.$ c.r.a $]$ & -9.75 & -9.75 & -10 & -10 & -9.75 & -9.75 & -10 & -10 \\
\hline$P_{e}[\mathrm{~kW}]$ & 17.21 & 17.22 & 16.62 & 16.53 & 7.64 & 7.64 & 7.27 & 7.19 \\
\hline$b_{e}[\mathrm{~g} / \mathrm{kW} \cdot \mathrm{h}]$ & 198.5 & 198.4 & 205.5 & 206.7 & 197 & 197.1 & 207.2 & 209.4 \\
\hline$P_{\max }[\mathrm{bar}]$ & 126.8 & 127.2 & 120.2 & 117.6 & 79.7 & 79.4 & 66.2 & 63 \\
\hline$P_{k}[$ bar $]$ & 3.17 & 3.17 & 3.15 & 3.16 & 1.54 & 1.54 & 1.55 & 1.55 \\
\hline$\alpha[-]$ & 2.23 & 2.23 & 2.22 & 2.23 & 2.55 & 1.77 & 2.57 & 2.58 \\
\hline$T_{t}[\mathrm{~K}]$ & 725 & 725 & 724 & 726 & 647 & 647 & 651 & 654 \\
\hline$T_{g}[\mathrm{~K}]$ & 591 & 591 & 591 & 591 & 601 & 602 & 605 & 607 \\
\hline$\tau_{i}\left[{ }^{\circ}\right.$ c.r.a $]$ & 3.75 & 3.97 & 9.51 & 10.6 & 5.19 & 5.48 & 13.13 & 14.82 \\
\hline
\end{tabular}

Table B2. Influence of MBF properties on diesel engine ChN 26.5/31 parameters

\begin{tabular}{|c|c|c|c|c|c|c|c|c|}
\hline \multirow{3}{*}{$\begin{array}{c}\text { Parameter } \\
\text { Make }\end{array}$} & \multicolumn{8}{|c|}{ Load } \\
\hline & \multicolumn{4}{|c|}{$100 \%$} & \multicolumn{4}{|c|}{$25 \%$} \\
\hline & DMA & DMA & DMA & $\mathrm{DMB}$ & DMA & DMA & DMA & $\mathrm{DMB}$ \\
\hline$\rho\left[\mathrm{kg} / \mathrm{m}^{3}\right]$ & 810 & 830 & 850 & 900 & 810 & 830 & 850 & 900 \\
\hline$v\left[\mathrm{~mm}^{2} / \mathrm{s}\right]$ & 6 & 2 & 4 & 2 & 6 & 2 & 4 & 2 \\
\hline$n\left[\min ^{-1}\right]$ & 1000 & 1000 & 1000 & 1000 & 755 & 755 & 755 & 755 \\
\hline$H_{u}[\mathrm{MJ} / \mathrm{kg}]$ & 43.22 & 42.99 & 42.76 & 42.15 & 43.22 & 42.99 & 42.76 & 42.15 \\
\hline$E_{a}[\mathrm{~kJ} / \mathrm{mol}]$ & 19.21 & 29.53 & 26.81 & 39.16 & 19.21 & 29.53 & 26.81 & 39.16 \\
\hline$\varphi_{i n j}\left[{ }^{\circ}\right.$ c.r.a $]$ & -14.5 & -14.5 & -14.5 & -14.5 & -14.5 & -14.5 & -14.5 & -14.5 \\
\hline$P_{e}[\mathrm{~kW}]$ & 25.95 & 26.39 & 27 & 26.85 & 10.27 & 10.19 & 10.1 & 9.18 \\
\hline$b_{e}[\mathrm{~g} / \mathrm{kW} \cdot \mathrm{h}]$ & 207 & 208.4 & 208.5 & 222 & 225.6 & 227.4 & 229.1 & 252.6 \\
\hline$P_{\max }[$ bar $]$ & 194.6 & 199.5 & 206 & 193.7 & 117.3 & 112.7 & 114 & 71.61 \\
\hline$P_{k}[\mathrm{bar}]$ & 4.25 & 4.32 & 4.36 & 4.74 & 1.67 & 1.66 & 1.65 & 1.77 \\
\hline$\alpha[-]$ & 1.93 & 1.9 & 1.87 & 1.9 & 1.76 & 1.74 & 1.73 & 1.87 \\
\hline$T_{t}[\mathrm{~K}]$ & 899 & 896 & 901 & 916 & 825 & 833 & 830 & 867 \\
\hline$T_{g}[\mathrm{~K}]$ & 741 & 737 & 740 & 744 & 762 & 771 & 768 & 795 \\
\hline$\tau_{i}\left[{ }^{\circ}\right.$ c.r.a $]$ & 5.36 & 7.05 & 6.3 & 18.68 & 7.03 & 9.63 & 8.6 & 28.07 \\
\hline
\end{tabular}


Table B3. Influence of MBF properties on diesel engine MTU 8V 396TB parameters

\begin{tabular}{|c|c|c|c|c|c|c|c|c|c|}
\hline \multirow{3}{*}{$\begin{array}{c}\text { Parameter } \\
\text { Make }\end{array}$} & \multicolumn{9}{|c|}{ Load } \\
\hline & \multicolumn{4}{|c|}{$100 \%$} & \multicolumn{5}{|c|}{$25 \%$} \\
\hline & DMA & $\mathrm{DMB}$ & DMA & $\mathrm{DMB}$ & DMA & $\mathrm{DMB}$ & DMA & $\mathrm{DMB}$ & $\mathrm{DMB}$ \\
\hline$\rho\left[\mathrm{kg} / \mathrm{m}^{3}\right]$ & 810 & 810 & 830 & 900 & 810 & 810 & 830 & 900 & 900 \\
\hline$v\left[\mathrm{~mm}^{2} / \mathrm{s}\right]$ & 6 & 9 & 2 & 2 & 6 & 9 & 2 & 2 & 6 \\
\hline$n\left[\min ^{-1}\right]$ & 1850 & 1850 & 1850 & 1850 & 1400 & 1400 & 1400 & 1400 & 1400 \\
\hline$H_{u}[\mathrm{MJ} / \mathrm{kg}]$ & 43.22 & 43.22 & 43.00 & 42.15 & 43.22 & 43.22 & 43.00 & 42.15 & 42.15 \\
\hline$E_{a}[\mathrm{~kJ} / \mathrm{mol}]$ & 19.21 & 17.52 & 29.53 & 39.16 & 19.21 & 17.52 & 29.53 & 39.16 & 31.59 \\
\hline$\varphi_{i n j}\left[{ }^{\circ}\right.$ c.r.a $]$ & -5.75 & -5.75 & -6.00 & -6.72 & -5.75 & -5.75 & -6.00 & -6.72 & -6.72 \\
\hline$P_{e}[\mathrm{~kW}]$ & 12.09 & 12.11 & 12.33 & 13 & 4.36 & 4.37 & 4.34 & 4.14 & 4.23 \\
\hline$b_{e}[\mathrm{~g} / \mathrm{kW} \cdot \mathrm{h}]$ & 210.1 & 209.7 & 211.17 & 217.1 & 229.7 & 229.4 & 230.61 & 241.8 & 237.04 \\
\hline$P_{\max }[$ bar $]$ & 128.5 & 129.4 & 126.7 & 121.3 & 78.06 & 77.62 & 72.87 & 59.72 & 71.26 \\
\hline$P_{k}[\mathrm{bar}]$ & 2.08 & 2.08 & 2.12 & 2.24 & 1.16 & 1.16 & 1.16 & 1.17 & 1.16 \\
\hline$\alpha[-]$ & 1.76 & 1.75 & 1.75 & 1.71 & 2.6 & 2.6 & 2.61 & 2.64 & 2.61 \\
\hline$T_{t}[\mathrm{~K}]$ & 890 & 899 & 896 & 911 & 656 & 657 & 662 & 676 & 658 \\
\hline$T_{g}[\mathrm{~K}]$ & 818 & 818 & 812 & 821 & 639 & 639 & 644 & 657 & 640 \\
\hline$\tau_{i}\left[{ }^{\circ}\right.$ c.r.a $]$ & 2.8 & 2.5 & 5.2 & 11.2 & 3.1 & 2.9 & 6.1 & 14.3 & 7.6 \\
\hline
\end{tabular}

\section{References}

Abbe, C.; Nzengwa, R.; Danwe, R.; Ayissi, Z.; Obounou, M. 2013. Simulation of a DI diesel engine performance fuelled on biodiesel using a semi-empirical 0D model, Energy and Power Engineering 5(10): 596-603.

https://doi.org/10.4236/epe.2013.510066

Anfindsen, O. J.; Løvoll, G.; Mestl, T. 2012. Benchmarking of marine bunker fuel suppliers: the good, the bad, the ugly, Benchmarking: an International Journal 19(1): 109-125. https://doi.org/10.1108/14635771211218399

Armas, O.; Mata, C.; Martínez-Martínez, S. 2012. Effect of diesel injection parameters on instantaneous fuel delivery using a solenoid- operated injector with different fuels, Revista Facultad de Ingeniería Universidad de Antioquia (64): 9-21.

Cataluña, R.; Da Silva, R. 2012. Effect of cetane number on specific fuel consumption and particulate matter and unburned hydrocarbon emissions from diesel engines, Journal of Combustion 2012: 738940. https://doi.org/10.1155/2012/738940

Centeno-González, F. O.; Mahkamov, K.; Silva Lora, E. E.; Andrade, R. V.; Jaén, R. L. 2013. Prediction by mathematical modeling of the behavior of an internal combustion engine to be fed with gas from biomass, in comparison to the same engine fueled with gasoline or methane, Renewable Energy 60: 427-432. https://doi.org/10.1016/j.renene.2013.05.037

CIMAC. 2011. Fuel Quality Guide - Ignition and Combustion. International Council on Combustion Engines (CIMAC). 25 p. Available from Internet: https://www.cimac.com/publications/publications350/cimac-wg07-fuel-quality-guide-ignition-and-combustion.html

EC. 2011. White Paper on Transport: Roadmap to a Single European Transport Area: Towards a Competitive and Resource Efficient Transport System. European Commission (EC). 28 p. https://doi.org/10.2832/30955

Eurostat. 2021. Greenhouse Gas Emission Statistics - Emission Inventories. European Statistics. Available from Internet: https://ec.europa.eu/eurostat/statistics-explained/index.
php?title=Greenhouse_gas_emission_statistics_-_emission_ inventories

Fayyazbakhsh, A.; Pirouzfar, V. 2017. Comprehensive overview on diesel additives to reduce emissions, enhance fuel properties and improve engine performance, Renewable and Sustainable Energy Reviews 74: 891-901.

https://doi.org/10.1016/j.rser.2017.03.046

Fostiropoulos, S.; Strotos, G.; Nikolopoulos, N.; Gavaises, M. 2020. Numerical investigation of heavy fuel oil droplet breakup enhancement with water emulsions, Fuel 278: 118381. https://doi.org/10.1016/j.fuel.2020.118381

Fun-Sang Cepeda, M. A.; Pereira, N. N.; Kahn, S.; Caprace, J.-D. 2019. A review of the use of LNG versus HFO in maritime industry, Marine Systems \& Ocean Technology 14(2-3): 75-84. https://doi.org/10.1007/s40868-019-00059-y

García-Olivares, A.; Solé, J.; Osychenko, O. 2018. Transportation in a $100 \%$ renewable energy system, Energy Conversion and Management 158: 266-285.

https://doi.org/10.1016/j.enconman.2017.12.053

Han, D.; Li, K.; Duan, Y.; Lin, H.; Huang, Z. 2017. Numerical study on fuel physical effects on the split injection processes on a common rail injection system, Energy Conversion and Management 134: 47-58.

https://doi.org/10.1016/j.enconman.2016.12.026

Helgason, R.; Cook, D.; Davíðsdóttir, B. 2020. An evaluation of the cost-competitiveness of maritime fuels - a comparison of heavy fuel oil and methanol (renewable and natural gas) in Iceland, Sustainable Production and Consumption 23: 236248. https://doi.org/10.1016/j.spc.2020.06.007

IMO. 2021. Initial IMO GHG Strategy. International Maritime Organization (IMO). Available from Internet: https://www. imo.org/en/MediaCentre/HotTopics/Pages/Reducing-greenhouse-gas-emissions-from-ships.aspx

ISO 8217:2017. Petroleum Products - Fuels (Class F) - Specifications of Marine Fuels. Available from Internet:

https://www.iso.org/standard/64247.html 
Jang, S. H.; Choi, J. H. 2016. Comparison of fuel consumption and emission characteristics of various marine heavy fuel additives, Applied Energy 179: 36-44.

https://doi.org/10.1016/j.apenergy.2016.06.122

Kim, Y.-R.; Jung, M.; Park, J.-B. 2021. Development of a fuel consumption prediction model based on machine learning using ship in-service data, Journal of Marine Science and Engineering 9(2): 137. https://doi.org/10.3390/jmse9020137

Kuan, Y.-H.; Wu, F.-H.; Chen, G.-B.; Lin, H.-T.; Lin, T.-H. 2020. Study of the combustion characteristics of sewage sludge pyrolysis oil, heavy fuel oil, and their blends, Energy 201: 117559. https://doi.org/10.1016/j.energy.2020.117559

Kuleshov, A. S. 2004. Programma rascheta i optimizacii dvigatelej vnutrennego sgoranija DIZEL'-RK. Opisanie matematicheskih modelej, reshenie optimizacionnyh zadach. Moskva: MGTU im. Baumana. 123 s. (in Russian).

Labeckas, G.; Pauliukas, A.; Slavinskas, S. 2006. The effect of fuel additive SO-2E on diesel engine performance when operating on diesel fuel and shale oil, Transport 21(2): 71-79.

https://doi.org/10.3846/16484142.2006.9638046

Lakshminarayanan, P. A.; Aghav, Y. V. 2010. Modelling Diesel Combustion. Springer. 305 p.

https://doi.org/10.1007/978-90-481-3885-2

Lassesson, H.; Andersson, K. 2009. Energy Efficiency in Shipping: Review and Evaluation of the State of Knowledge. Report No. 09:115. Chalmers University of Technology, Goteborg, Sweden. $37 \mathrm{p}$.

Li, L.; Loo, B. P. Y. 2014. Alternative and transitional energy sources for urban transportation, Current Sustainable/Renewable Energy Reports 1(1): 19-26.

https://doi.org/10.1007/s40518-014-0005-6

Liu, H.; Ma, J.; Dong, F.; Yang, Y.; Liu, X.; Ma, G.; Zheng, Z.; Yao, M. 2018. Experimental investigation of the effects of diesel fuel properties on combustion and emissions on a multicylinder heavy-duty diesel engine, Energy Conversion and Management 171: 1787-1800.

https://doi.org/10.1016/j.enconman.2018.06.089

Lundh, M.; Garcia-Gabin, W.; Tervo, K.; Lindkvist, R. 2016. Estimation and optimization of vessel fuel consumption, IFACPapersOnLine 49(23): 394-399.

https://doi.org/10.1016/j.ifacol.2016.10.436

Maawa, W. N.; Mamat, R.; Najafi, G.; De Goey, L. P. H. 2020. Performance, combustion, and emission characteristics of a CI engine fueled with emulsified diesel-biodiesel blends at different water contents, Fuel 267: 117265. https://doi.org/10.1016/j.fuel.2020.117265

MFAME. 2015. Major Damage to the Engines! Neglect of One Important Parameter in the Fuel Quality Test Report. Marine Fuels and Marine Engine (MFAME) Team. Available from Internet: https://mfame.guru/major-damage-to-the-enginesneglect-of-one-important-parameter-in-the-fuel-quality-testreport/

Mollenhauer, K.; Tschöke, H. 2010. Handbook of Diesel Engines. Springer. 636 p. https://doi.org/10.1007/978-3-540-89083-6

Monyem, A.; Van Gerpen, J. H.; Canakci, M. 2001.The effect of timing and oxidation on emissions from biodiesel-fueled engines, Transactions of the ASAE 44(1): 35-42.

https://doi.org/10.13031/2013.2301

Moreira, L.; Vettor, R.; Guedes Soares, C. 2021. Neural network approach for predicting ship speed and fuel consumption, Journal of Marine Science and Engineering 9(2): 119. https://doi.org/10.3390/jmse9020119
Olmer, N.; Comer, B.; Roy, B.; Mao, X.; Rutherford, D. 2017. Greenhouse Gas Emissions from Global Shipping, 2013-2015. International Council on Clean Transportation (ICCT), Washington, DC, US. 38 p. Available from Internet: https://theicct. org/publications/GHG-emissions-global-shipping-2013-2015

Panapakidis, I.; Sourtzi, V.-M.; Dagoumas, A. 2020. Forecasting the fuel consumption of passenger ships with a combination of shallow and deep learning, Electronics 9(5): 776. https://doi.org/10.3390/electronics9050776

Reif, K. 2014. Diesel Engine Management: Systems and Components. Springer. $370 \mathrm{p}$.

https://doi.org/10.1007/978-3-658-03981-3

Schobert, H. 2013. Chemistry of Fossil Fuels and Biofuels. Cambridge University Press. $497 \mathrm{p}$.

https://doi.org/10.1017/CBO9780511844188

Shuverov, V. M.; Shirkunov A. S.; Juhnev, V. A.; Sereda, V. V. 2015. Toplivnaja kompozicija flotskogo mazuta (varianty) Fuel Composition of Bunker Oil (Versions). Patent Rossijskoj Federacii RU2581034C1. (in Russian). Available from Internet: https://patents.google.com/patent/RU2581034C1/ru

Soto, F.; Alves, M.; Valdés, J. C.; Armas, O.; Crnkovic, P.; Rodrigues, G.; Lacerda, A.; Melo, L. 2018. The determination of the activation energy of diesel and biodiesel fuels and the analysis of engine performance and soot emissions, Fuel Processing Technology 174: 69-77. https://doi.org/10.1016/j.fuproc.2018.02.008

Takasaki, K.; Fukuyoshi, T.; Abe, S.; Nakashima, M.; Osafune, S.N. 1999. Visual study about combustion characteristics of heavy fuel in diesel engines, Bulletin of the Marine Engineering Society in Japan 27(1): 22-28.

Tat, M. E.; Van Gerpen, J. H. 2003. Measurement of Biodiesel Speed of Sound and Its Impact on Injection Timing. Final Report NREL/SR-510-31462. Report 4 in a Series of 6. National Renewable Energy Laboratory (NREL), Golden, CO, US. 120 p. https://doi.org/10.2172/15003584

Tat, M. E.; Van Gerpen, J. H.; Soylu, S.; Canakci, M.; Monyem, A.; Wormley, S. 2000. The speed of sound and isentropic bulk modulus of biodiesel at $21^{\circ} \mathrm{C}$ from atmospheric pressure to $35 \mathrm{MPa}$, Journal of the American Oil Chemists' Society 77(3): 285-289. https://doi.org/10.1007/s11746-000-0047-z

Totten, G.; Shah, R.; Forester, D. 2019. Fuels and Lubricants Handbook: Technology, Properties, Performance, and Testing. 2nd Edition. ASTM International. 1709 p.

https://doi.org/10.1520/MNL37-2ND-EB

Tuti, M.; Şahin, Z.; Durgun, O. 2017. Thermodynamic diesel engine cycle modeling and prediction of engine performance parameters, Journal of Ship and Marine Technology (207): 14-26. Available from Internet: https://www.journalagent. com/gmo/pdfs/GMO_23_207_14_26.pdf

Voznickij, I. V.; Punda, A. S. 2010. Sudovye dvigateli vnutrennego sgoranija. Tom 1. Sankt-Peterburg: Morkniga. 260 s. (in Russian).

Wakuri, Y.; Takasaki, K.; Maeda, K.; Yang, Y. X.; Okubo, H.; Hino, S. 1990. Residual fuel sprays - evaporation, dispersion and combustion characteristics, in COMODIA 90: Proceedings of the International Symposium on Diagnostics and Modeling of Combustion in Internal Combustion Engines, 3-5 September 1990, Kyoto, Japan, 539-544. Available from Internet: https://www.jsme.or.jp/esd/COMODIA-Procs/Data/002/ C90_P539.pdf

Wilkison, J. 1985. A review of U.S. marine fuel oil availability and quality - present and future, in C. Jones (Ed.). Marine Fuels, 28-42. https://doi.org/10.1520/STP35270S 
Wright, G. 2017. Fundamentals of Medium/Heavy Duty Diesel Engines. CDX Automotive. 1394 p.

Xing, Y.; Yang, H.; Ma, X.; Zhang, Y. 2019. Optimization of ship speed and fleet deployment under carbon emissions policies for container shipping, Transport 34(2): 260-274. https://doi. org/10.3846/transport.2019.9317

Yan, R.; Wang, S.; Du, Y. 2020. Development of a two-stage ship fuel consumption prediction and reduction model for a dry bulk ship, Transportation Research Part E: Logistics and Transportation Review 138: 101930. https://doi.org/10.1016/j. tre.2020.101930

Zannis, T. C.; Hountalas, D. T.; Papagiannakis, R. G. 2007. Experimental study of diesel fuel effects on direct injection (di) diesel engine performance and pollutant emissions, Energy \& Fuels 21(5): 2642-2654. https://doi.org/10.1021/ef070149x

Zheng, Z.; Badawy, T.; Henein, N.; Sattler, E. 2013. Investigation of physical and chemical delay periods of different fuels in the ignition quality tester, Journal of Engineering for Gas Turbines and Power 135(6): 061501. https://doi.org/10.1115/1.4023607 